Documentación de las Ciencias de la Información ISSN: 0210-4210

http://dx.doi.org/10.5209/DCIN.61402

\title{
El archivo de Radiotelevisión Valenciana: sobrevivir, migrar e integrar con À Punt
}

\author{
Lola Alfonso $^{1}$; Paz Orero ${ }^{2}$
}

Recibido: 28 de agosto de 2018 / Aceptado: 21 de octubre de 2018

Resumen. Tras el cierre de Radiotelevisión Valenciana (RTVV), su archivo ha sido conservado y preservado como bien común que refleja la historia, la cultura y la lengua de la Comunidad Valenciana. Este artículo repasa cronológicamente la gestión documental y la salvaguarda de los fondos audiovisuales desde 2013, año de la clausura de RTVV, hasta 2018, momento en el que se produce la integración con À Punt, el nuevo medio de comunicación público valenciano.

Palabras clave: Archivos audiovisuales; Archivos de televisión; Digitalización; Gestión documental; Patrimonio audiovisual; RTVV; À Punt.

[en] Radiotelevisión Valenciana archive: survive, migrate, and integrate into À Punt

Abstract. After the closure of Radiotelevisión Valenciana (RTVV), its archive has been preserved as a common asset representing the history, culture and language of the Valencian Community. This article offers a chronological review of the documentary management and the safeguard of the audiovisual assets developed from 2013, when RTVV was shut down, until 2018, when its archive was integrated into À Punt, the new Valencian public media.

Keywords: Audiovisual archives, Television archives; Digitization; Documentary Management; Audiovisual Heritage; RTVV; À Punt.

Sumario. 1. Introducción. 2. Supervivencia: trabajando por la preservación del patrimonio audiovisual valenciano (2013-2018). 3. Migración: del sistema de gestión Tarsys a VSNExplorer. 4. Integración con la nueva televisión pública valenciana: À Punt 5. Conclusiones. 6. Referencias bibliográficas.

Cómo citar. Alfonso, L.; Orero, P. (2018) El archivo de Radiotelevisión Valenciana: sobrevivir, migrar e integrar con À Punt en Documentación de las Ciencias de la Información 41, 19-29.

\footnotetext{
1 Institut Valencià de Cultura alfonso_mdonog@gva.es

2 Institut Valencià de Cultura orero_margarb@gva.es
} 


\section{Introducción}

«El patrimonio audiovisual ofrece, mediante imágenes y sonido, una visión singular del pasado como base para mirar al futuro. [...] Este patrimonio, que establece un vínculo entre el pasado y el presente, forma parte de nuestra historia común y ha de ser salvaguardado y compartido como fuente de identidad y de pertenencia, innovación y creatividad» ${ }^{3}$.

Salvar el archivo audiovisual de Radiotelevisión Valenciana (RTVV) ha sido la acción más directa para preservar la memoria audiovisual reciente de la Comunidad Valenciana. Frente a unas circunstancias excepcionales -el cierre abrupto de los medios de comunicación públicos valencianos- la continuidad de un grupo de profesionales de la Unidad de Documentación de RTVV ha permitido salvaguardar el fondo documental y continuar con la labor de digitalización iniciada en el año 2006. Las condiciones han sido complejas al tener que desarrollarse en una empresa en extinción, en un centro de producción de televisión vacío, con una tecnología que comenzaba a ser obsoleta y sin apenas soporte técnico externo. Un tiempo de resiliencia para guarecer el patrimonio audiovisual generado entre 1989 y 2013 por los trabajadores de la radio y la televisión publica valenciana.

La situación actual del archivo de RTVV continúa siendo excepcional. Lo es desde el 29 de noviembre del año 2013 en el que el gobierno valenciano ejecutó la decisión política del cierre de la empresa y aplicó la Ley 4/2013 ${ }^{4}$ de Supresión de la Prestación de los Servicios de Radiodifusión y Televisión de Ámbito Autonómico, de Titularidad de la Generalitat Valenciana, así como de Disolución y Liquidación de Radiotelevisión Valenciana SAU. La medida generó un grave impacto social, laboral y humano, y también interrogantes sobre la preservación de los fondos acumulados durante más de veinticuatros años de emisión. Los soportes analógicos comenzaban a mostrar síntomas de degradación física y era urgente su digitalización, mientras que los digitales requerían el mantenimiento de una costosa infraestructura técnica para la gestión, preservación y acceso. Pese a la protección legal eran necesarios recursos para continuar con la transformación y digitalización del archivo audiovisual más importante de la Comunidad Valencianas.

La negociación entre la empresa y los representantes legales de los trabajadores culminó en el acuerdo final del periodo de consultas del despido colectivo. En el apartado tercero de medidas sociales de acompañamiento se estableció la recolocación en un organismo público de 23 empleados de la Unidad de Documentación -frente a los 1600 que fueron despedidos- para realizar las funciones propias del

Bokova, Irina. Día Mundial del Patrimonio Audiovisual 2017. Mensaje de la Directora General. Disponible en: https://es.unesco.org/wdah2017/dg-message. [Consulta 21 de julio 2018].

4 Comunidad Valenciana. Ley 4/2013, de 27 de noviembre, de la Generalitat, de Supresión de la Prestación de los Servicios de Radiodifusión y Televisión de Ámbito Autonómico, de Titularidad de la Generalitat, así como de Disolución y Liquidación de Radiotelevisión Valenciana, SAU. Diari Oficial de la Generalitat Valenciana, núm. 7161 de 27 de noviembre de 2013. Disponible en: https://www.dogv.gva.es/portal/ficha_disposicion_pc. jsp?sig=010860/2013\&L=1 [Consulta 15 de julio 2018].

5 Alfonso Noguerón, Lola y Buigues García, Mar. El fondo documental audiovisual de Radiotelevisión Valenciana: evolución, Transformación y Bien de Interés Cultural. Patrimonio audiovisual de la Comunitat Valenciana. Métodos de información (MEI), II época, 2014, vol. 5, núm. 8, pp. 59-74. Disponible en: http://dx.doi. org/10.5557/IIMEI5-N8-059074 
departamento de documentación (archivo histórico documental y audiovisual). En junio de 2014, tras la baremación entre los profesionales que cumplían con los requisitos establecidos, se completó el equipo.

El acuerdo entre empresa, sindicatos e inspección de trabajo se sustanció en la aplicación de la Ley 7/2014 de Medidas Fiscales, de Gestión Administrativa y Financiera, y de Organización de la Generalitat. En el artículo 129.5 se detallaba que la entidad pública CulturArts se haría cargo de la gestión y custodia del archivo y de su personal, aunque la titularidad de los fondos continuaría en manos de la mercantil RTVV SAU:

«Con la finalidad de dar cumplimiento al acuerdo alcanzado entre la comisión de los representantes de los trabajadores de RTVV y el Consejo de Liquidación de RTVV, de fecha 23 de marzo de 2014, el personal laboral adscrito al archivo de documentación de Radiotelevisión Valenciana, SAU, se adscribirá al ente público CulturArts Generalitat, siendo este ente público, a partir de la fecha de incorporación efectiva del referido personal, el responsable de la gestión y custodia del archivo documental de RTVV soportando el coste que ello comporte. La titularidad del archivo documental de RTVV corresponderá, en principio, a la mercantil Radiotelevisión Valenciana, SAU, en tanto no haya concluido el proceso de liquidación de la referida sociedad» ${ }^{6}$.

Esta medida fue efectiva el 1 de julio de 2015 con la cesión como unidad productiva autónoma a CulturArts, actualmente Institut Valencià de Cultura (IVC), bajo la Dirección Adjunta de Audiovisuales y Cinematografía.

\section{Supervivencia: trabajando por la preservación del patrimonio audiovisual valenciano (2013-2018)}

Como el resto de las televisiones de nuestro entorno, RTVV no era un organismo de preservación, sino un operador público de televisión cuyo centro de documentación periodística y audiovisual tenía un doble espíritu?:

- Una herramienta empresarial que ayudaba a rentabilizar la producción y la emisión de los diversos canales del medio proporcionando la información documental requerida y mediante la explotación de fragmentos audiovisuales, la reemisión de programas y la venta de imágenes.

- Un archivo patrimonial que conservaba y trataba un material audiovisual único reflejo de la actualidad informativa y los acontecimientos sociales, políticos, culturales, territoriales y deportivos de la Comunidad Valenciana en las últimas décadas que «quizá en muchos casos y precisamente por su condición

6 Comunidad Valenciana. Ley 7/2014, de 22 de diciembre, de Medidas Fiscales, de Gestión Administrativa y Financiera, y de Organización de la Generalitat. Diari Oficial de la Generalitat Valenciana, núm. 7432 de 29 de diciembre de 2014. Disponible en:https://www.dogv.gva.es/portal/ficha_disposicion_pc.jsp?si$\mathrm{g}=011461 / 2014 \& \mathrm{~L}=1$ [Consulta 15 de julio de 2018].

7 Conesa, Alícia. La documentación en los medios de comunicación audiovisuales. En: Fuentes i Pujol, $\mathrm{M}^{\mathrm{a}}$ Eulàlia. Manual de documentación periodística. Madrid: Síntesis, 1995, pp. 147-159. 
de acontecimientos locales, sólo existen en este fondo documental. A esta condición hay que sumar otro valor añadido, el hecho de que en su inmensa mayoría es un fondo documental en lengua valenciana» ${ }^{8}$.

Con el fin de las emisiones y la liquidación de RTVV, el propósito empresarial quedaba extinguido por lo que los equipos, herramientas y personal de la Unidad de Documentación se concentraron en el objetivo de la salvaguarda patrimonial. Durante más de cuatro años se ha trabajado inventariando y digitalizando los materiales porque como en cualquier archivo de televisión, «l'objectiu no és la conservació d'uns suports, sinó assegurar la preservació i l'accés permanent dels documents audiovisuals, les imatges i els sons que contenen» ${ }^{9}$.

El fondo de RTVV es generalista y multiformato: más de 280.000 cintas de vídeo en soporte profesional, materiales digitalizados conservados en cintas robotizadas en fichero IMX30 (MPEG2 D10 a 30Mbps encapsulado en MXF),XDCAM HD (XDCAM50 HD 4:2:2 A 50 Mbps), formatos domésticos como DVD; más de 7.700 libros; 100 cabeceras de publicaciones periódicas en la hemeroteca; un archivo sonoro (ficheros PCM Estéreo 48Khz 16 bit WAV) y musical de las emisoras de radio en diversos soportes (CD, DVD, casetes, DAT, minidiscos, etc.).

\begin{tabular}{|l|l|}
\hline Inventario fondo RTVV 2014-2016 & Número de materiales \\
\hline Hemeroteca & 22887 \\
\hline Fonoteca & 5668 \\
\hline Biblioteca & 7717 \\
\hline Discoteca & 49675 \\
\hline Audiovisual & 280221 \\
\hline Audiovisual doméstico & 13152 \\
\hline Total & $\mathbf{3 9 0 4 8 2}$ \\
\hline
\end{tabular}

Las grabaciones audiovisuales se conservaban con una descripción y tratamiento documental orientado a los usuarios de radio y de televisión, donde la rapidez en el caso de los informativos y la exhaustividad necesaria para la producción de programas, marcaban la estructura de la información de los diversos sistemas de gestión documental. Convivían 30 bases de datos referenciales y un sistema de gestión de contenidos multimedia que permitía la recuperación de los materiales audiovisuales desde cualquier puesto de trabajo.

Estas bases de datos -todas ellas en valenciano-, así como los sistemas de naturaleza tecnológica eran igualmente elementos susceptibles de la protección y preservación, puesto que son herramientas que permiten la localización de los documentos. Por ello, no se debía menospreciar su valor.

8 Hidalgo Goyanes, Paloma. El Archivo Audiovisual de RTVV: Patrimonio Audiovisual de la Humanidad. Métodos de información (MEI), II Época, 2014, vol. 5, núm. 8, pp. 17-30. Disponible en: http://dx.doi.org/10.5557/ IIMEI5-N8-017030

9 Conesa, Alícia. De la videoteca a l'arxiu digital: evolució del Departament de Documentació de Televisió de Catalunya. Trípodos, 2013, núm. 31, pp. 99-108. Disponible en: https://www.raco.cat/index.php/Tripodos/article/ viewFile/262075/349257 


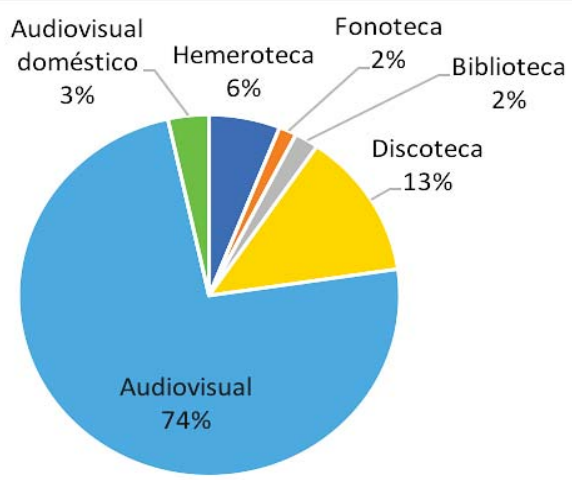

INVENTARIO FONDOS RTVV 2014-2016

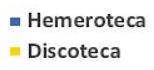

= Fonoteca
= Audiovisual

- Biblioteca

= Audiovisual doméstico

La política de preservación ha seguido el modelo del Institut Nacional de l'Audiovisual (INA) y las recomendaciones de los organismos internacionales como la Unesco o la Federación Internacional de Archivos de Televisión (FIAT/IFTA), aunque lo verdaderamente complejo fue la selección y priorización de los materiales que debían convertirse en fichero digital por motivos económicos y documentales. Se continuaba con la labor iniciada en 2006, pero las necesidades habían variado sustancialmente. Desde 2013 y durante varios años se desconocía el destino del centro documental y quiénes serían sus futuros usuarios. También dificultó dicha selección el desconocimiento de los derechos de uso y/o los contratos con las distribuidoras o productoras, información que estaba en el Departamento Jurídico ya inexistente. Pese a todo, las circunstancias tan atípicas propiciaron una serie de ventajas respecto a las cadenas en funcionamiento: el tiempo entre la grabación y la emisión ofrecía una perspectiva valiosa para evaluar la importancia de las grabaciones y obras audiovisuales. A la vez, no existía la presión de la producción, la línea editorial o el modelo empresarial y la totalidad de los recursos se destinaban a la salvaguarda patrimonial del fondo documental.

El proyecto pasaba por la definición del objeto de digitalización, la cantidad del material que debía digitalizarse para cada serie, los criterios y pautas para evaluar el material y los plazos de ejecución ${ }^{10}$.

La metodología seguida partió de la elaboración de listados por años (1989-2013) a partir de la metadata del campo «procedencia de las imágenes» y del número ID -código único e irrepetible de cada programa o grabación- que también identificaba si era una producción propia, ajena o coproducción. Se distinguieron los programas seriados de los únicos, así como las retransmisiones y especiales, tanto de carácter general como deportivo. Tal y como aconseja la FIAT, se priorizó la producción propia y, a continuación, se aplicó un cuádruple criterio: obsolescencia del soporte físico, puesto que algunas cintas Betacam empezaban a mostrar signos de deterioro; derechos sobre la imagen; relevancia temática (interés social, informativo, histórico y corporativo); y cobertura equilibrada de las distintas etapas de las cadenas.

10 Giménez Rayo, Mabel. Documentación audiovisual de televisión: la selección del material. Gijón: Trea, 2007. ISBN: 9788497043205. 
En muchas ocasiones los documentos audiovisuales de televisión se conservan duplicados desde un punto de vista de imagen. Un máster de emisión es idéntico en contenido a un editado -también llamado premáster o compactado- pero no lo es desde un punto de vista técnico. En este último el documento está limpio de rótulos y los audios separados y es el que solicita redacción o realización para reutilizar las imágenes del archivo. En cambio, si se quiere ver el documento audiovisual tal como fue emitido, se debe conservar el máster. Esta dualidad también condicionó la digitalización del fondo documental y se evaluó para cada serie qué material debía preservarse de forma prioritaria.

Se dio preferencia a los documentos audiovisuales producidos por los servicios informativos diarios -Notícies Nou-, no diarios de temática general y especializada-Dossiers, Minut a Minut, Corts Valencianes, Encontres o Colp d'Ull-y especiales informativos. En todos ellos se digitalizó la totalidad de la colección y en la doble dirección expuesta anteriormente: el paralelo de antena y los editados/compactados.

Toda la ficción y los documentales fueron convertidos a ficheros digitales por su elevado coste de producción. Por otro lado, se realizó una preservación selectiva del máster de emisión de géneros repetitivos como concursos, programas infantiles o tertulias por la limitación de los recursos materiales y tecnológicos vividos en esta etapa.

Finalmente, los brutos y originales de cámara también recibieron una preservación selectiva. Se aplicaron los criterios señalados anteriormente y se añadió el de la relación con la serie. Esto es, se certificaba si el resto de material audiovisual para el que fueron grabados esos originales (máster de emisión, editados o compactados) había sido ya transformado digitalmente.

En 2018, el fondo digitalizado es de aproximadamente 60.000 horas, el 40-50\% de la producción propia, entre las que se incluyen los materiales sonoros y los relacionados con la creación ajena pero con doblaje al valenciano.

El proceso de digitalización sirvió además para realizar tareas de depuración de metadata y de enriquecimiento del análisis documental en aquellos materiales que tenían únicamente un tratamiento de registro e identificación básica.

\section{Migración: del sistema de gestión Tarsys a VSNExplorer}

La incorporación del equipo directivo de la Corporació Valenciana de Mitjans de Comunicació (CVMC) agilizó la actualización de los sistemas técnicos de Documentación que era imprescindible mejorar -la robótica de las cintas Petasite de Sony S2000, hoy descatalogada; cintas de datos LTO5 y drives; la SAN (Stornext) redundante; el software de gestión Tarsys, etc.-.

El 8 de agosto del año 2017 se publicó en el $\mathrm{BOE}^{11}$ el anuncio de licitación del suministro e instalación de la ampliación y actualización del sistema automatizado de documentación (expediente CNMY17/CVMC/06 ${ }^{12}$ ). En noviembre de 2017

11 España. Anuncio de licitación de: Corporació Valenciana de Mitjans de Comunicació. Objeto: Suministro e instalación de la ampliación y actualización del sistema automatizado de documentación. Expediente: CNMY17/ CVMC/06. Boletín Oficial del Estado, núm. 188 de 8 de agosto de 2017, sec. V-A. pág. 58782. Disponible en: https://www.boe.es/boe/dias/2017/08/08/pdfs/BOE-B-2017-47890.pdf. [Consulta 16 de agosto de 2018].

12 Ministerio de Hacienda. Pliego de prescripciones técnicasCNMY17/CVMC/06 Suministro e instalación 
el contrato fue adjudicado ${ }^{13}$ a la empresa Servicios Integrales Unitecnic SLU para la provisión de un conjunto de equipos y sistemas que permitieran a la CVMC la actualización de la librería de cintas y la gestión de la misma, un almacenamiento intermedio como repositorio temporal de contenidos, una aplicación para la gestión documental, un sistema de copia legal de las emisiones de la CVMC, una herramienta de transcodificación para los contenidos del portal web correspondiente y un procedimiento de ingesta de los materiales retrospectivos de RTVV.

Para cubrir las necesidades recogidas en el pliego con respecto a la gestión de contenidos del archivo, desde Unitecnic se propuso el sistema MAM VSNEXPLORER del fabricante Video Stream Network (VSN) para mover, buscar, recuperar, transcodificar y organizar toda la media. Basado en el sistema central VSNSpider puede gestionar vídeo, audio, imágenes y documentos, integrarse con otros sistemas de almacenamiento, controlar librerías LTO y ODS e interactuar con plataformas en la nube. También dispone del módulo de Bussiness Intelligence que ofrece un conjunto de herramientas de auditoría e informes analíticos para analizar el rendimiento de la gestión y uso de los contenidos y detectar ineficiencias en sus procesos y tendencias. Este módulo permite generar y extraer informes a partir de información existente en el sistema, sin necesidad de llevar a cabo esta tarea manualmente.

En las primeras semanas de 2018 comenzó la instalación del hardware, mientras se instalaron las máquinas y los equipos el personal de documentación, en colaboración con los responsables de la integración y migración, trabajó en la depuración de los metadatos y en el nuevo modelo de datos, basado en los estándares de los que se disponía, pero también investigando en los internacionales ${ }^{14}$ que se han ido implementando en los últimos años en el audiovisual. Se estableció un mapeo y unas reglas de migración para mejorar la calidad de los metadatos ajustándose a las características propias y a las nuevas necesidades de los archivos multimedia.

Tras el desarrollo teórico, se inició la fase de migración de metadata y media desde Tarsys -grabaciones y obras televisivas- y BRS/BKM -fondo sonoro de la radioal nuevo gestor VSNExplorer. A la vez se abordó la definición y puesta en marcha de los flujos de trabajo y la integración con los nuevos sistemas de producción, edición y emisión de la CVMC.

Durante la migración del contenido de las cintas LTO5 a LTO7se han mantenido activas las dos robóticas hasta que finalice el proceso. El material del fondo RTVV en resolución SD y con relación de aspecto 4:3 se ha migrado en el formato nativo y se continúa la digitalización retrospectiva en MPEG2 4:2:2 P 30 Mbps (D10) en contenedor MXF Op1a, según estándar SMPTE 386M.

de la ampliación y actualización del sistema automatizado de documentación. Disponible en: Plataforma de contratación de sector público. Disponible en: https:/contrataciondelestado.es/wps/wcm/connect/20f629db-35db-4d11-800b-6a0f2c5913af/DOC20170803181355CNMY17+CVMC+06+PPT.pdf?MOD=AJPERES. [Consulta 21 de julio 2018].

13 Ministerio de Hacienda. Licitaciones. Expediente: CNMY17/CVMC/06. Disponible en: Plataforma de contratación de sector público. Disponible en:https:/contrataciondelestado.es/wps/portal/!ut/p/b1/ hZBPC4JAFMQ_kbznuq11NP_srliapuVeYiGThbRLRPTpU6FLkL3bwG9mHgMKaosSe0WZy-AIqtcP0-q7ufX6CjUo5Z68Ktx5cuUgz7MQyTp3GY3SQSJUnX6azryaM-yhlmOAYicapr4fCYLLwgmQJEFZMjFKMgD1AOCP83Dy_yrEj3_h-LSKq4wVkiNKEQVJaS-QE_bPfwA1IXMJEzD34nwJwlbcuuZ7vHSdD1vE2WafcWIjsnGxGDplLJVfCmnx9g2GC7PM/ [Consulta 16 de agosto de 2018].

14 Polo Carrión, Juan Antonio, Caldera Serrano, Jorge y Poveda López, Inés Carmen. Metadatos y audiovisual: iniciativas, esquemas y estándares. En: Documentación de las Ciencias de la Información 2011, vol. 34, pp. 45-64. Disponible en: http://dx.doi.org/10.5209/rev_DCIN.2011.v34.36445 
El sistema de archivo permite la recuperación parcial de la cinta y la posibilidad de externalizar la cinta de datos, si llega a ser necesario. Existe un servidor que hace las funciones de archivo intermedio, si se requiere, para aquellos materiales que no se desean llevar al espacio del archivo profundo.

Cuando el lector tenga este texto en sus manos, la migración de la media seguirá realizándose, si bien, la de los metadatos (1.200.000 assets del archivo televisivo) estará completada. También habrá finalizado la importación de los assets de la fonoteca de las emisoras de radio de RTVV. Muchos de estos assets son exclusivamente datos del análisis documental (sin media asociada), pero que son vitales para seguir digitalizando las cintas de video y audio que se conservan.

\section{Integración con la nueva televisión pública valenciana: À Punt}

Con la puesta en marcha de los nuevos medios de comunicación públicos de la Comunidad Valenciana, en la primavera del año 2018 se firmó un convenio entre la Corporació Valenciana de Mitjans de Comunicació (CVMC) y la dirección del Institut Valencià de Cultura (IVC) para que el personal de la Unidad de Documentación pasara a gestionar y archivar el fondo documental audiovisual, sonoro y fotográfico generado por estos medios cuya marca comercial es À Punt. A la vez, se autorizaba el acceso y uso del fondo documental de RTVV para las producciones de la nueva radio, televisión y plataforma web.

El archivo de la extinta RTVV, como patrimonio de todos los valencianos, permite conocer gran parte de la historia reciente de esta comunidad, por lo que su preservación y puesta en valor debe ser un compromiso de las entidades públicas. En esa línea, las Corts Valencianes han aprobado la Ley10/2018 ${ }^{15}$ de creación del Consell del Audiovisual de la Comunitat Valenciana (CACV). En el capítulo IV propone la creación del Archivo Audiovisual:

«Se crea el Archivo Audiovisual de la Comunitat Valenciana para coordinar los archivos y fondos audiovisuales de la Generalitat y sus instituciones, en especial los archivos del Institut Valencià de Cultura y los de la Radiotelevisió Valenciana, SAU, en liquidación, así como de aquellas otras instituciones públicas o privadas que quieran adherirse»

Y a continuación detalla:

«Los fondos documentales que conforman el conjunto documental de la extinta RTVV podrán cederse para su difusión y explotación, en los términos que determine el Consell de l'Audiovisual de la Comunitat Valenciana y conforme a los derechos que puedan existir sobre los mismos, a los prestadores del servicio de comunicación audiovisual, públicos y privados, con título habilitante otorgado por la Generalitat»

15 Comunidad Valenciana. Ley 10/2018, de 18 de mayo, de la Generalitat, de creación del Consell del Audiovisual de la Comunitat Valenciana (CACV). Diari Oficial de la Generalitat Valenciana, núm. 8301 de 23 de mayo de 2015. Disponible en: https://www.dogv.gva.es/portal/ficha_disposicion_pc.jsp?sig=005100/2018\&L=1[Consulta 15 de julio de 2018]. 
Más allá de lo que ocurra tras la aprobación de esta ley y la puesta en marcha de estas entidades, el personal de Documentación de la antigua RTVV mantiene vivo el propósito de salvaguarda patrimonial, de manera firme y en la línea de lo que fue el eslogan de la celebración del Día Mundial de Patrimonio audiovisual 2017: «Descubrir, recordar y compartir».

Un archivo superviviente que desde la primavera del 2018 entró en una etapa de frenética actividad para asegurar la preservación digital y facilitar el acceso a los materiales tanto de RTVV como de À Punt. Se trabaja para archivar digitalmente desde el inicio de las emisiones, consolidar flujos de trabajo de los medios que ahora nacen, seguir con la digitalización retrospectiva, reconsiderar la metodología de análisis documental acorde con la llegada de metadatos por flujos automáticos, definir y asentar con coherencia las rutinas de selección, y cubrir el vacío informativo del periodo 2013-2017 originado por el cierre de RTVV.

La singularidad y excepcionalidad permanecen en el centro de documentación de la primera televisión y radio públicas de la Comunidad Valenciana, que ahora también lo es de la segunda. La salvaguarda del patrimonio audiovisual tiene que continuar y, por supuesto, el archivo debería aspirar a lograr una mayor difusión. Desde hace unos meses participa activamente en la elaboración de las producciones de À Punt, pero una vez resuelto el acceso para los profesionales y empresas del sector audiovisual, el próximo reto es permitir vía web la accesibilidad al sector académico y a los ciudadanos. «Conservar los documentos no es por sí mismo un fin para los profesionales de los archivos de las televisiones. Se conservan con el claro propósito de que puedan ser reutilizados, de que la información que contienen se transmita a través del tiempo y el espacio y de que los usuarios potenciales puedan acceder a ella» ${ }^{16}$.

\section{Conclusiones}

A pesar de las limitaciones tecnológicas, humanas y presupuestarias, durante el último lustro se ha trabajado en la salvaguarda patrimonial del archivo de la extinta Radiotelevisión Valenciana (RTVV). Las incógnitas legales, incertidumbres sobre el destino del fondo y la insólita realidad de ser un departamento superviviente en el expediente de regulación de empleo han provocado dudas a la hora de tomar decisiones de carácter técnico y documental.

Se ha continuado con la digitalización de los fondos de producción propia de los canales del grupo RTVV mediante criterios racionales para asegurar la conservación y uso en optimas condiciones respetando los derechos de autor y conexos. La insólita situación de persistencia del centro de documentación en un medio de comunicación cerrado ha originado que se aplicaran unos criterios de digitalización no condicionados por la línea editorial ni por el modelo de negocio, aspectos inherentes en una empresa en producción. El objetivo principal ha sido proteger el fondo audiovisual propio, memoria histórica colectiva de la sociedad valenciana, aplicando criterios de obsolescencia, derechos sobre la imagen, relevancia temática y representación equi-

16 Hidalgo Goyanes, Paloma. Prevenir la amnesia colectiva: El acceso público a los archivos de televisión. Documentación de las Ciencias de la Información, 2013, vol. 36, pp. 143-166. Disponible en: http://dx.doi. org/10.5209/rev_DCIN.2013.v36.42946 
librada de las distintas etapas de las emisoras. Todo ello con la aspiración final de la puesta en valor de los fondos gracias a la llegada de los medios de comunicación públicos y con la apertura a instituciones, docentes, empresas y ciudadanía en este contexto actual de acceso universal al conocimiento en línea.

El nacimiento de À Punt ha permitido poner el fondo documental de RTVV al servicio del nuevo medio de comunicación, al tiempo que los profesionales que lo custodiaban han pasado a ofrecer los servicios tradicionales de los centros de documentación periodísticos adaptados a la era digital.

\section{Bibliografía}

Alfonso Noguerón, Lola y Buigues García, Mar. El fondo documental audiovisual de Radiotelevisión Valenciana: evolución, Transformación y Bien de Interés Cultural. Patrimonio audiovisual de la Comunitat Valenciana. Métodos de información (MEI), II época, 2014, vol. 5, núm. 8, pp. 59-74.

Bokova, Irina. Día Mundial del Patrimonio Audiovisual 2017. Mensaje de la Directora General. Disponible en: https://es.unesco.org/wdah2017/dg-message [Consulta 21 de julio 2018].

Changing sceneries, Changing Roles, part VII. (FIAT/IFTA Media Management Seminar, Glasgow, 21-22 May 2015) [s.1.]: FIAT/IFTA Media Comission, 2015. Disponible en: http://rdbg.tuxic.nl/fiatifta/wp-content/uploads/2015/11/Changing-Sceneries-Changing-Roles-VII_midres.pdf

Comunidad Valenciana. Ley 10/2018, de 18 de mayo, de la Generalitat, de creación del Consell del Audiovisual de la Comunitat Valenciana (CACV). Diari Oficial de la Generalitat Valenciana, núm. 8301 de 23 de mayo de 2015. Disponible en: https://www.dogv.gva.es/ portal/ficha_disposicion_pc.jsp?sig=005100/2018\&L=1 [Consulta 15 de julio de 2018].

Comunidad Valenciana. Ley 4/2013, de 27 de noviembre, de la Generalitat, de Supresión de la Prestación de los Servicios de Radiodifusión y Televisión de Ámbito Autonómico, de Titularidad de la Generalitat, así como de Disolución y Liquidación de Radiotelevisión Valenciana, SAU. Diari Oficial de la Generalitat Valenciana, núm. 7161 de 27 de noviembre de 2013. Disponible en:https://www.dogv.gva.es/portal/ficha_disposicion_pc.jsp?sig $=010860 / 2013 \& \mathrm{~L}=1$ [Consulta 15 de julio de 2018].

Comunidad Valenciana. Ley 7/2014, de 22 de diciembre, de Medidas Fiscales, de Gestión Administrativa y Financiera, y de Organización de la Generalitat. Diari Oficial de la Generalitat Valenciana, núm. 7432 de 29 de diciembre de 2014. Disponible en: https:// www.dogv.gva.es/portal/ficha_disposicion_pc.jsp?sig=011461/2014\&L=1 [Consulta 15 de julio de 2018].

Conesa, Alícia. De la videoteca a l'arxiu digital: evolució del Departament de Documentació de Televisió de Catalunya. Trípodos, 2013, núm. 31, pp. 99-108. Disponible en: https:// www.raco.cat/index.php/Tripodos/article/viewFile/262075/349257

Conesa, Alícia. La documentación en los medios de comunicación audiovisuales. En: Fuentes i Pujol, Ma Eulàlia. Manual de documentación periodística. Madrid: Síntesis, 1995, pp. 147-159.

España. Anuncio de licitación de: Corporació Valenciana de Mitjans de Comunicació. Objeto: Suministro e instalación de la ampliación y actualización del sistema automatizado de documentación. Expediente: CNMY17/CVMC/06. Boletín Oficial del Estado, núm. 188 
de 8 de agosto de 2017, sec. V-A. pág. 58782. Disponible en: https://www.boe.es/boe/ dias/2017/08/08/pdfs/BOE-B-2017-47890.pdf. [Consulta 16 de agosto de 2018].

Giménez Rayo, Mabel. Documentación audiovisual de televisión: la selección del material. Gijón: Trea, 2007. ISBN: 9788497043205.

Hidalgo Goyanes, Paloma. El Archivo Audiovisual de RTVV: Patrimonio Audiovisual de la Humanidad. Métodos de información (MEI), II Época, 2014, vol. 5, núm. 8, pp. 17-30. Disponible en: http://dx.doi.org/10.5557/IIMEI5-N8-017030

Hidalgo Goyanes, Paloma. Prevenir la amnesia colectiva: El acceso público a los archivos de televisión. Documentación de las Ciencias de la Información, 2013, vol. 36, pp. 143-166. Disponible en: http://dx.doi.org/10.5209/rev_DCIN.2013.v36.42946

Ministerio de Hacienda. Licitaciones. Expediente: CNMY17/CVMC/06. Disponible en: Plataforma de contratación de sector público. Disponible en: https://contrataciondelestado.es/ wps/portal/!ut/p/b1/hZBPC4JAFMQ_kbznuq11NP_srliapuVeYiGThbRLRPTpU6FLkL3bwG9mHgMKaosSe0WZy-AIqtcP0-q7ufX6CjUo5Z68Ktx5cuUgz7MQyTp3GY3SQSJUnX6azryaM-yhlmOAYicapr4fCYLLwgmQJEFZMjFKMgD1AOCP83Dy_yrEj3_h-LSKq4wVkiNKEQVJaS-QE_bPfwA1IXMJEzD34nwJwlbcuuZ7vHSdD1vE2WafcWIjsnGxGDplLJVfCmnx9g2GC7PM/ [Consulta 16 de agosto de 2018].

Ministerio de Hacienda. Pliego de prescripciones técnicasCNMY17/CVMC/06 Suministro e instalación de la ampliación y actualización del sistema automatizado de documentación. Disponible en: Plataforma de contratación de sector público. Disponible en: https:// contrataciondelestado.es/wps/wcm/connect/20f629db-35db-4d11-800b-6a0f2c5913af/ DOC20170803181355CNMY17+CVMC+06+PPT.pdf?MOD=AJPERES[Consulta 21 de julio 2018].

Polo Carrión, Juan Antonio, Caldera Serrano, Jorge y Poveda López, Inés Carmen. Metadatos y audiovisual: iniciativas, esquemas y estándares. En: Documentación de las Ciencias de la Información 2011, vol. 34, pp. 45-64. Disponible en: http://dx.doi.org/10.5209/ rev_DCIN.2011.v34.36445

Tapia, Alicia, et al. La memoria del periodismo. En: Anàlisi: quaderns de comunicació $i$ cultura, 2006, núm. 33, pp. 119-133. Disponible en: https://core.ac.uk/download/ pdf/13270125.pdf 